\title{
The carbon footprint of a public sector University before and during the COVID-19 lockdown
}

\author{
Haseeb M. ${ }^{1}$, Tahir Z. ${ }^{1}$, Batool S.A. ${ }^{2}$, Majeed A. ${ }^{3 *}$, Ahmad S.R. ${ }^{1}$ and Kanwal S. ${ }^{4}$ \\ ${ }^{1}$ College of Earth and Environmental Science, University of the Punjab, Pakistan \\ ${ }^{2}$ Remote Sensing, GIS and Climate Change Research Lab (National Center of GIS and Space Applications), Department of Space Sciences, \\ University of the Punjab, Pakistan \\ ${ }^{3}$ Department of Environmental Science, Faculty of Agriculture and Environment, The Islamia University of Bahawalpur, Pakistan \\ ${ }^{4}$ Institute of Energy and Environmental Engineering, University of the Punjab, Pakistan \\ Received: 11/12/2021, Accepted: 26/12/2021, Available online: 04/01/2022 \\ *to whom all correspondence should be addressed: e-mail: asmamajeedrana@gmail.com \\ https://doi.org/10.30955/gnj.004222
}

\section{Graphical abstract}

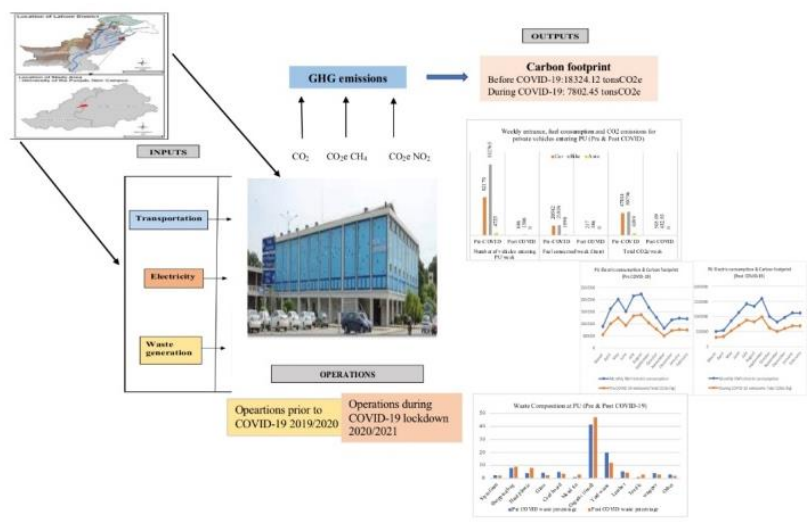

\section{Abstract}

Carbon footprint (CF) is a measure of greenhouse gas emissions generated from daily human-induced activities as carbon dioxide equivalent. This study is an attempt to represent a consumption-based CF study from the scope of transportation, electricity, and waste generation for University of the Punjab (PU), Lahore under the WRI/WBCSD greenhouse gas protocol corporate standards. Data acquired through fieldwork, questionnaire surveys, direct sampling, and existing records for the year 2019-20 suggested that electricity is the greatest contributor of $\mathrm{CO}_{2}$ emissions at 59\%, followed by transportation at $36 \%$, and waste generation at approximately $5 \%$. The total $\mathrm{CF}\left(\mathrm{CO}_{2}\right.$ eq $)$ generated from different sources is about $18360.62 \mathrm{MT}$ for one year. The recent COVID-19 lockdown has offered inimitable prospect to compare the carbon footprint of one of the largest higher education institutes of Pakistan before and during this pandemic. The data can serve for tracking, assessing, and setting goals for greenhouse gas emission reduction programs in future.

Keywords: Carbon footprint; Greenhouse emissions; COVID-19; energy consumption; Solid waste generation.

$\begin{array}{ll}\text { Abbreviations } & \\ \text { WRI } & \text { World resources institute } \\ \text { WBCSD } & \begin{array}{l}\text { World business council for sustainable } \\ \text { development }\end{array} \\ \text { IPCC } & \text { Intergovernmental panel on climate change } \\ \mathrm{CO}_{2} \mathrm{e} / \mathrm{CO}_{2} \text { eq } & \text { Carbon dioxide equivalent } \\ \mathrm{MTCO}_{2} & \text { Metric tons of carbon dioxide } \\ \text { UNO } & \text { United nation organizations } \\ \text { UNEP } & \text { United nation for environmental protection }\end{array}$

1. Introduction

According to the United States green building council (USGBC, 2010), the green campus is a higher education community aimed at improving its energy efficiency, resources management, and environmental quality through sustainable education, healthy living, and comfortable learning environments for everyone (Hussain et al., 2019). Academia is an important stakeholder towards sustainability achievement (Findler et al., 2019). Higher education institutions, in particular, can play a key role in capacity building among youth to stipulate a basis towards the promotion of the global agenda for sustainable development (Disterheft et al., 2019). Almost 1400 universities around the world have supported and signed sustainability in higher education declarations (Ridhosari and Rahman 2020). However, the case can be quite contradictory especially in developing countries where most educational institutes are unenlightened and less responsible regarding their roles and obligations towards environmental improvement and may contribute to unsustainability through excessive exploitation of resources and associated GHG emissions (Jarillo et al., 2019). The United Nations Organization recently established the Higher Education Sustainability Initiative (2020) on a global scale that necessitates significant accountability into the customary set-ups of higher education institutions around the world (Bao 2020). This 
initiative aims to engage more universities and colleges around the world in the achievement of the United Nations Sustainable Development Goals (UNSDG) (Cebrián and Junyent 2015). Such activities highlight the need for and importance of academia's commitment to achieving longterm sustainability goals (Education and Development 2020).

Carbon footprinting is a technique to find an aggregate of all $\mathrm{GHGs}$ as $\mathrm{CO}_{2}$ eq, emitted directly or indirectly from different anthropogenic activities including fuel, electricity consumption, waste production, mining activities, food \& beverages production, construction, and other daily activities (Yan et al., 2019). Realizing the need for climate change mitigation several organizations have initiated programs to measure their carbon footprint. Universities are recognized as key promoters to ensure long-term transformation and perpetuation of reforms in a society (Lorena et al., 2013). Several studies have been conducted regarding the estimation of carbon footprint in various universities and colleges globally in recent years. Such practices can help keep the trail and assess practices that can have negative effects on the climate.

The COVID-19 pandemic has huge impacts on most aspects of human activities, as well as on the economy, health care, and educational system (Ahorsu et al., 2020; Filimonau et al., 2020). The government of Pakistan imposed a countrywide forced lockdown on $24^{\text {th }}$ March in schools, colleges, and universities to prevent the spread of disease. This halt in educational activities owing to restricted mobility and less exploitation of resources has provided a unique opportunity to focus on identifying the magnitude of environmental improvement through bringing certain reforms in our unrestrained consumption behaviors to achieve long-term environmental benefits (Murphy 2020).

The paper is a first attempt to identify major sources of GHGs emission and to quantify the total carbon footprint at any higher education institute in Pakistan as the data can become a source to get a better understanding of campus existing carbon footprint dynamics and provides the basis for tracking, assessing and setting goals for greenhouse gas emission reduction program. An attempt was also made to compare the carbon footprint during university closure in vague of the COVID-19 pandemic. Such comparative studies can demonstrate the relative contribution of various operations to GHG emissions associated with traditional higher education practices and help to set benchmarks for future evaluation and determine the extent of policymaking and management interventions needed to reduce the carbon footprints in the studied institution.

Pakistan is one of the top nations with a high climate change vulnerability index (Khan and Siddiqui 2017). At present, the country's GHG emissions are growing at $6 \%$ per annum i.e. 18.5 million of carbon dioxide $\left(\mathrm{CO}_{2} \_\right.$eq) equivalent. In 2008 the emissions were 147.8 million tons of $\mathrm{CO}_{2}$ eq (sheikh and tunio 2015) which are expected to reach 400 million tons of $\mathrm{CO}_{2}$ equivalent per year by 2030 (Mustafa 2015). University of the Punjab is one of the oldest and largest centers of higher education in Lahore,
Pakistan. Founded in 1882, PU offers a wide range of graduate and post-graduate programs on two campuses, Quaid-e-Azam campus (new campus) and Allama lqbal campus (old campus) (Figures 1-3).

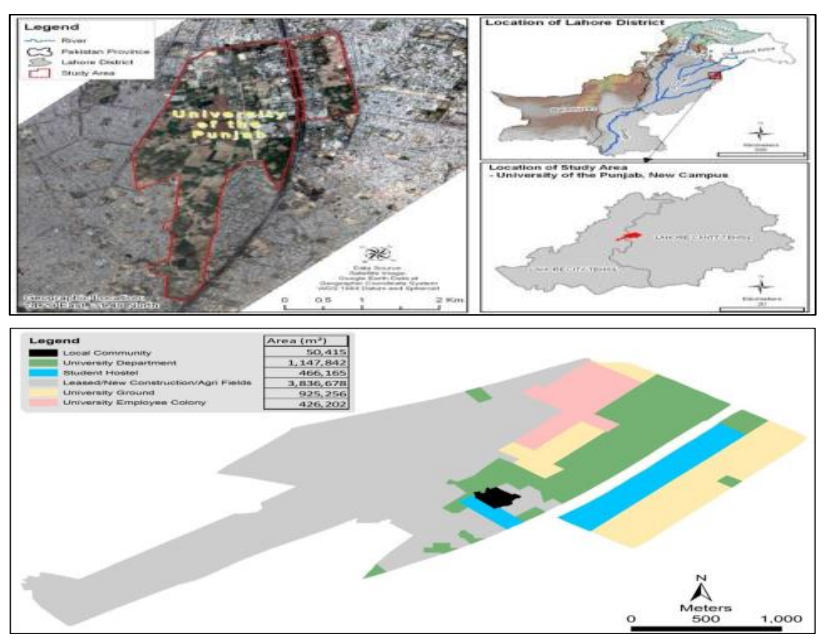

Figure 1. Map of the study area (The University of the Punjab).

\subsection{System boundary for carbon footprint assessment}

The University of Punjab, Quaid e Azam campus has been selected for the present study of CF assessment. The campus is located near the canal road district Lahore in Punjab, Pakistan. A closer look reveals that the total area of $\mathrm{PU}$ new campus is $6,802,143 \mathrm{~m}^{2}$. A total of 73 educational departments occupies an area of $1147842 \mathrm{~m}^{2}$. As of March 2020, there were 45678 enrolled students and 1006 fulltime and 300 part-time academic staff while almost 10,000 employees have been working in the university. Students and staff from all over Pakistan are part of this institution so a large area has been allocated for hostels and employee residence. The hostel area comprises thirty-one hostels, nineteen are kept for boys and 12 hostels are reserved for girls. While the residential colony occupies an area of $426,202 \mathrm{~m}^{2}$ comprising of houses, quarters, and flats for university personnel.

Various methods have been employed by several researchers to assess carbon footprint that varies from complex to simplified life cycle assessment (LCA), simplified energy analysis to the employment of input-output method (Hendrickson et al., 1998; PE International 2013; Rana et al., 2020; Sevenster, 2013; Šenitková and Bednárová 2015). For our study, a simple LCA has been employed. This research provides a consumption-based carbon footprint study for University of the Punjab, Lahore to characterize different activities which are contributing to its carbon footprint under the WRI/WBCSD greenhouse gas protocol corporate standard (WBCSD and WRI 2012). Carbon footprint data collected from different sources were obtained for the academic year 2019-2020 on the university campus. The data were further compared against the generated CF for 2020-21 i.e. during the COVID19 lockdown period. The selection of chosen period for comparative analysis was determined by the partial opening of the university for research activities. 


\section{Methodology}

Electricity, transportation, and waste generation have been chosen as target research elements as they are highly carbon-intensive and mainly contribute to GHG emissions. CF assessment of PU incorporated direct emissions from transportation activities (Scope 1) indirect emissions from electricity usage for various daily operations within the campus (Scope 2) and other GHGs emissions from solid waste generation and management activities (Scope 3). The primary and secondary data were acquired through many approaches. Field and questionnaire surveys were carried out to collect firsthand information. Questionnaires were filled up through mini interviews from students, faculty members, administrative employees, drivers, canteen owners, and guards, etc throughout the campus. The secondary data was acquired from research journals, published reports, and documents from relevant sources.

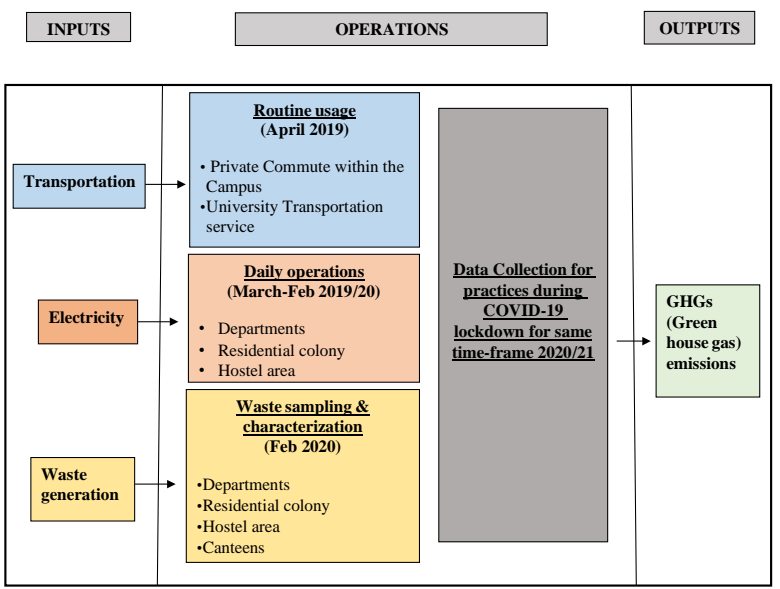

Figure 2. Overview of the system boundary for carbon footprint assessment.

Total $\mathrm{CO}_{2}$ emissions from transportation activity include the emission from the university's busses and other private vehicles used by the faculty and students in the university area. The data relating to fuel consumption through transportation was gathered through monitoring the daily commute activity. Each car, bus, rickshaw, bike, or any other transport means entering the campus were monitored and data was recorded for a period of one month i.e. April 2020. A questionnaires survey was also conducted for estimations of the Number of vehicles (private and university's), total distance traveled, and type of fuel used. Questionnaires having 35 questions were distributed to 445 students and 155 teachers, while 180 interviews were also conducted throughout the campus. The students who use bikes and the private car and rickshaw drivers were interviewed to calculate the distance traveled in the university. Three types of questions were asked in each interview that include the type of fuel being used, the distance traveled inside the university boundary, and the average consumption of used fuel.

Fuel consumption related to university-owned transport was extracted through fuel consumption records of the university and gauging the total distance traveled by the busses through calculating each route distance. Carbon emissions were calculated from these transportation sources based on the fuel used. The study only concerns traveling within the university premises, travelling of students and faculty home through means other than university transport is not included in our system boundary. Calculation of the total CF was carried out by identifying the type of fuel used by transportation and then multiplying the emission factor for each type of fuel.

Emissions from electricity are considered indirect emissions. The data about electricity consumption at PU for the academic year 2019/20 and 20/21was extracted from the university records available at the campus directorate office. Electricity supports the buildings used for learning and research activities, facility cooling and heating operations, and student support activities like communication and printing etc. Emission factors for producing and consuming electricity have schemed following the particular country's energy mix (Brander 2012). Pakistan's energy mix comprises $64 \%$ fossil fuel, $27 \%$ hydropower, and $9 \%$ renewable/ nuclear sources. Thermal and coal-based electricity generation leads to high GHG emission levels. Pakistan's specific emissions are relatively less as they are based on oil, natural gas, and hydroelectric power generation. Total carbon emissions for the consumption of electricity for a year were obtained by multiplying the total KWh used in one year to a factor of $0.615374995 \mathrm{Kg} \mathrm{CO}_{2} / \mathrm{kWh}$.

To estimate the quantity and composition of solid waste generated in the PU campus a preliminary field study was conducted. There are many protocols to assess the solid waste composition and generation including ASTM Method, ADEME Method, CIWMB Method, RVF Method, SAEFL Method (Owojori et al., 2020). An established method (ASTM) has been used to determine the waste composition (Krook et al., 2012). This is the best suitable method for the study area. The ASTM method suggests 91$136 \mathrm{~kg}$ (200-300lb) of sub-sample weight as a suitable representative for characterization studies (Dahlén and Lagerkvist 2008). The samples were collected from the final disposal site i.e. Sagian pull and from the campus waste collection trolleys. This sampling identified different components of waste being produced from four main sources 1) Teachers and staff residential area, 2) Boys and girls' hostels, 3) Academic and administrative Departments, and 4) Canteens. To get a representative sample, a sampling and characterization survey was performed on all seven days of a week. This study labeled waste into 16 different waste categories as Styrofoam, shopping bags, wrappers, plastics, papers, cardboard, metals, food waste, yard waste, leather, textile, glass, concrete, rubber, soil, and wood. The acquired waste data were analyzed through a Life Cycle Assessment (LCA) Model EASEWASTE to calculate the overall carbon emission related to the solid waste management system in practice. The model developed by the technical university of Denmark evaluates the environmental performance of various processes/treatments. $\mathrm{CO} 2$ emissions from waste generation are estimated by totting up the carbon emissions from disposal and transportation of waste. The 
carbon footprint has been calculated through the burning of fuel used to transport the waste to the dumping site and the degradation activity of organic waste at the dumping site where the model uses unique emission factors for each kind of waste material.

An expression to reflect the mathematics term for CF calculations:

$$
\mathrm{CF}\left(\mathrm{t} \mathrm{CO}{ }_{2} \mathrm{e}\right)=\sum \mathrm{in}=1(\mathrm{X} 1 \times \mathrm{F} 1)
$$

Where, X1 and F1 reflect the amount of energy (fuel, electricity) and emission factor for the type of energy utilized respectively (Yañez et al., 2019).

\section{Results and discussion}

This section presents the inventory data and results obtained by calculating the carbon footprints that have been generated at the New Campus University of the Punjab from three major sources i.e. electricity consumption, transportation and generation, and management of municipal solid waste before and during COVID-19 closure. Under normal circumstances, a major portion of PU's total carbon footprint can be assigned to transportation activities. The direct emissions are being generated from fuel (diesel and petrol) used on campus for transportation by student's private vehicles and institutional buses. PU owns many vehicles to aid in campus operations. There are a total of 55 busses (46 Big and 12 small) which cover approximately 126 routes (4929 $\mathrm{km}$ ). Five buses are used for shuttle services 9 for the employees ' children and others for specified routes. University buses use diesel fuel which produces $\mathrm{CO}_{2}$ emissions post-combustion. The average fuel consumption for Hino buses is about $2.75 \mathrm{KM} /$ liter and $4.75 \mathrm{~km} /$ liter for Rapid buses.

Three types of transportation sources are being used by the students and staff members for daily commute. Either they own cars and bikes or hire auto-rickshaws. The survey results represent that motorcycles are the most popular way of traveling within the campus with a percentage of $63 \%$ followed by cars at $34 \%$ and auto at $3 \%$ only. Motorcycles are mostly owned by students. Though the percentage between cars and motorcycles usage is different, the difference in their carbon emissions is relatively less significant (1.47 tons/day) that can be attributed to high efficiency and low average fuel consumption of motorcycles i.e., $35 \mathrm{KM} / \mathrm{L}$ in comparison to $12 \mathrm{KM} / \mathrm{L}$ for cars. On average 15554 cars entering the campus travel a distance of $46662 \mathrm{~km} /$ day, 29131 bikes cover an average distance of $145655 \mathrm{~km} /$ day while 903 autos entering the campus cover almost $9030 \mathrm{~km} / \mathrm{day}$. With an emission factor of $2.32 \mathrm{kgCO} 2 / \mathrm{l}$, the carbon footprint contributed by private transportation encompasses $49 \%$ emissions through motorcycles, $47 \%$ is contributed by cars while autos are responsible for $4 \%$ of total emissions. The calculations carried out to estimate the emissions contributed by different vehicles entering the university on different days of the week resulted in the graph presented here.

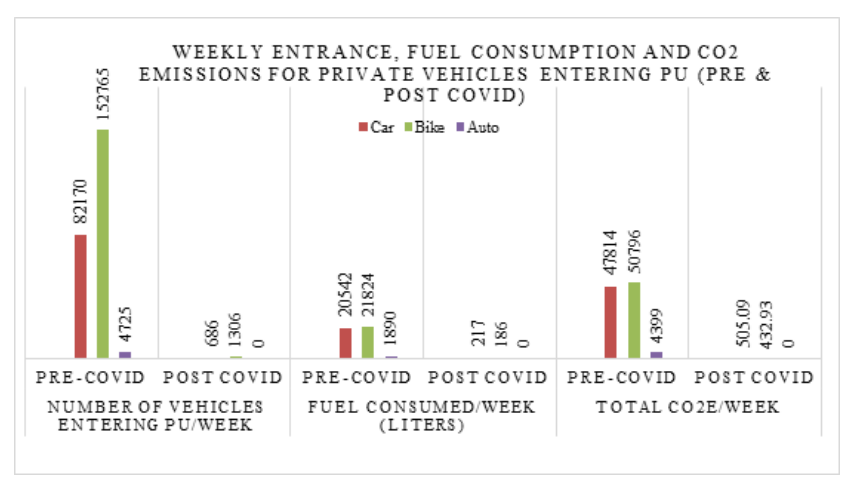

Figure 3. Weekly entrance, average fuel consumption, and $\mathrm{CO} 2$ emissions for private vehicles entering PU campus Pre and post COVID-19.

The university faced a forced lockdown due to COVID-19 in March 2020. All the academic activities were on halt. University transport operations were completely ceased. The students were not allowed to enter the premises while the administrative staff continued their services. The number of private transports entering the campus decreased with almost $84 \%$ fewer cars and $85 \%$ fewer bikes while the auto-rickshaws were completely banned within the facility so $100 \%$ fewer autos entered the campus. Consequently, there was a cut in the amount of fuel consumed and an overall 91\% less $\mathrm{CO} 2$ emissions resulting from a private vehicle. The table shows the daily, weekly, and yearly carbon footprint generation based on the type of transport, average distances traveled, and emission factor.

The results suggest that under normal circumstances (before COVID-19) approximate carbon emissions through transportation are 6519 tons (metric tons) yearly. Petrol is the biggest contributor with about 5371.235389 tons emissions per year followed by diesel which contributes almost 1147.8 tons of emissions per year. These emissions that decreased to $48911 \mathrm{Kg}$ of $\mathrm{CO} 2$ emissions post-COVID as the number of the vehicle entering the facility were decreased dramatically.

Energy emissions are taken as indirect emissions since while we devour energy we indirectly comprehend emissions that have been generated at the time of generation. Electricity consumption apprehends the largest share in the total carbon footprint of PU. Electricity is essential to support various research, teaching, and source supply operations such as water distribution and refrigeration. Electricity for the University of Punjab is provided by the water and power development authority (WAPDA), which supplies the energy to the customer in various regions throughout Pakistan. Total electricity consumption for the academic year 2019, including transmission and delivery losses, is $17696000 \mathrm{KWh}$. The emission factor for electricity is equal to $0.615374995 \mathrm{Kg}$ $\mathrm{CO}_{2}$ / KWh (Brander et al., 2011; Khan and Siddiqui 2017). Total carbon emissions due to the consumption of electricity are about 10913.82 tons yearly. Electricity is the highest contributor to GHG emission compared to other sectors in consideration. 
Table 1. Weekly $\mathrm{CO} 2$ emissions based on the emission factor and distance traveled

\begin{tabular}{|c|c|c|c|c|c|c|c|c|c|c|}
\hline \multirow[b]{2}{*}{$\begin{array}{l}\text { Type of } \\
\text { vehicle }\end{array}$} & \multicolumn{2}{|c|}{$\mathrm{CO}_{2}$} & \multicolumn{2}{|c|}{$\mathrm{CO}_{2} \mathrm{e} \mathrm{CH}_{4}$} & \multicolumn{2}{|c|}{$\mathrm{CO}_{2} \mathrm{e} \mathrm{NO}$} & \multicolumn{2}{|c|}{ Total $\mathrm{CO}_{2} \mathrm{e} /$ week } & \multicolumn{2}{|c|}{ Total $\mathrm{CO}_{2} \mathrm{e} /$ year } \\
\hline & $\begin{array}{l}\text { Pre- } \\
\text { COVID }\end{array}$ & $\begin{array}{l}\text { Post } \\
\text { COVID }\end{array}$ & $\begin{array}{l}\text { Pre- } \\
\text { COVID }\end{array}$ & $\begin{array}{l}\text { Post } \\
\text { COVID }\end{array}$ & $\begin{array}{l}\text { Pre- } \\
\text { COVID }\end{array}$ & $\begin{array}{l}\text { Post } \\
\text { COVID }\end{array}$ & $\begin{array}{l}\text { Pre- } \\
\text { COVID }\end{array}$ & Post COVID & Pre-COVID & $\begin{array}{c}\text { Post } \\
\text { COVID }\end{array}$ \\
\hline Car & 47715 & 504 & 47.78 & 0.505 & 51.61 & 0.545 & 47814 & 505.09 & 2493186 & 26336.68 \\
\hline Bike & 50691 & 432 & 50.76 & 0.433 & 54.83 & 0.467 & 50796 & 432.93 & 2648666 & 22574.30 \\
\hline Auto & 4390 & 0 & 4.40 & 0 & 4.75 & 0 & 4399 & 0 & 229384 & 0 \\
\hline Buses & 23699.8 & 0 & 33.17 & 0 & 179.84 & 0 & 23912.71 & 0 & 1147810.04 & 0 \\
\hline \multicolumn{7}{|c|}{ Total Emissions in KG } & 126921.7 & 938.02 & 6519046 & 48910.98 \\
\hline \multicolumn{7}{|c|}{ Total Emissions in MT } & 126.9217 & 0.9380 & 6519.046 & 48.911 \\
\hline
\end{tabular}

Figure 4 shows the optimal use of electricity pre and during COVID-19 closure. Under normal circumstances, electricity was used in all university departments including colonial areas and hostels. Post-COVID it's mainly utilized in the colonial area. The temporal breakdown is particularly important in this context. University closure was imposed in March, minimum electricity was consumed during March and April characterized by complete lockdown and pleasant weather. From May as the hot weather takes over added air conditioning leads to significant electricity consumption particularly for June, July, and August. September is characterized by the partial opening of the university; electricity was consumed in various departments as the research activity was resumed and the staff was allowed to take online classes. Relatively less consumption of electricity post-September can again be associated with fine weather and partial closure of the University. The resulting carbon footprint related to electricity usage including its consumption, distribution, and losses are shown in the form of a table here.

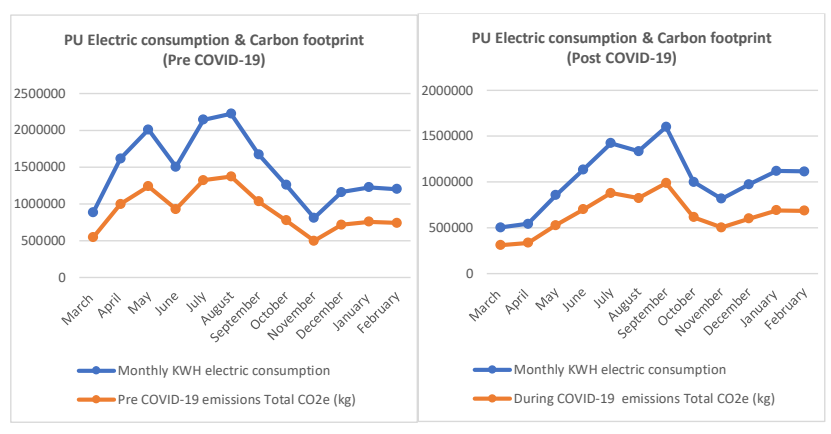

Figure 4. Monthly KWH electric consumption and $\mathrm{CO}_{2} \mathrm{e}$ emissions (Kg) pre and during COVID-19 closure.

The functional features of waste generation include handling, collection, transportation, storage, recover, recycle, reuse, treatment, and final disposal (Palanivel and Sulaiman, 2014). The approximate amount of waste generation at PU for the year $2019 / 20$ is about $6000 \mathrm{~kg}$ (6tons) per day. The annually produced waste consists of 643 tons of organic (food) waste, 444 tons of yard waste, 48 tons of hard plastic, and 47 tons of paper while the share of glass (116 tons) shopping bags (79 tons), and wrappers (70 tons) is also substantial. Six trolleys are used for the collection and transportation of generated waste and approximately $90 \mathrm{~L}$ fuel is consumed daily by these trolleys in a day. Generally, all of the generated waste is being disposed of in the landfill. The composition of the generated waste was found to vary with the source of generation and days of the week. Overall, the contribution of organic waste is higher in all samples followed by yard waste. It is observed through field surveys that most organic waste has been generated from hostels whereas paper, cardboard, packaging waste was found mostly in canteens and academic departments. Textile (1.42\%) and metal tin (1.40\%) are among the least found components in generated waste. The sampling characteristics of the waste generated at the study area before and during COVID lockdown are presented in Figures 4 and 5.

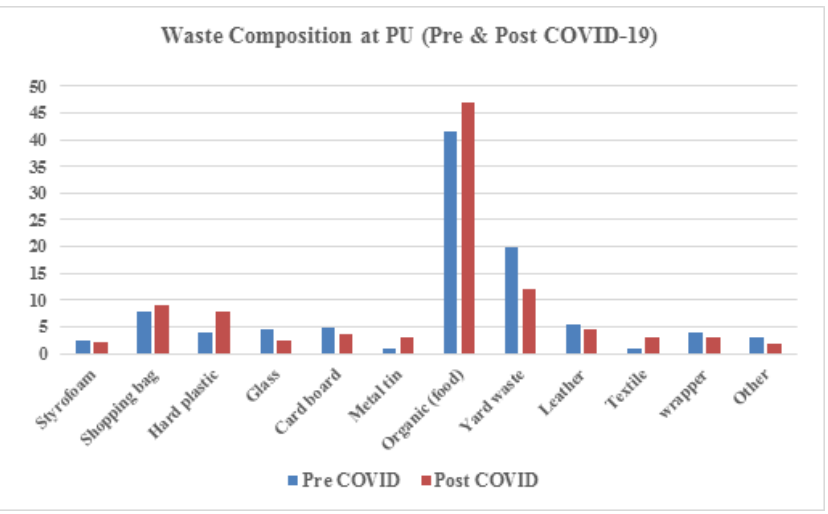

Figure 5. Percentage Composition of Generated Waste at PU (Pre and Post COVID-19).

The waste management sector contributes 2.3 tons of carbon emissions daily that comprises emissions including Nitrous oxide, Methane, carbon monoxide, CFCs, and Carbon dioxide. $\mathrm{CH} 4$ is the highest contributor due to the degradation of organic waste in open dumps. The field surveys reveal the fact that there are several meters high heaps of waste that flourish the anaerobic conditions over landfills which boost the emissions of GHG's at dumping sites. Owing to the presence of yard waste some carbon sequestration will occur at the same time. The presented carbon footprint was obtained after subtracting the carbon sequestration emissions from the total carbon emission. Total carbon footprint emissions from the waste management sector are 891.3 tons of which 88.3 tons are contributed through means used for waste handling and transportation (Tables 1-3).

During COVID-19 two trolleys were used to collect the waste and the approximate amount of waste for the year 2021 is around 2 tons $(2000 \mathrm{~kg}$ ) per day. Approximately $30 \mathrm{~L}$ of fuel is consumed by two trolleys in a day. 
Table 2.: $\mathrm{CO}_{2} \mathrm{e}$ kg production from generated waste at $\mathrm{PU}$

\begin{tabular}{cc}
\hline Substance name & CO $_{2}$-eq $\mathbf{~ K g}$ \\
\hline Carbon Sequestered [Air Emissions] & $-2,133.7584$ \\
\hline Carbon Dioxide ( $\mathrm{CO}_{2}$ - Fossil) [Air emissions] & 121.5772 \\
\hline Methane $\left(\mathrm{CH}_{4}\right)$ [Air emissions] & $4,212.4995$ \\
\hline Nitrous Oxide $\left(\mathrm{N}_{2} \mathrm{O}\right)[$ Air emissions] & 0.4468 \\
\hline Total $\mathrm{CO}_{2}$ e Emission (kg) & $\mathbf{8 9 1 3 0 0}$ \\
\hline
\end{tabular}

Table 3. Total Carbon Footprint in of The University of Punjab Pre and during COVID-19 in tons $\mathrm{CO}_{2} \mathrm{E}$

\begin{tabular}{ccccc}
\hline Emission source & $\begin{array}{c}\text { Carbon footprint pre } \\
\left.\text { COVID-19 (tons } \mathrm{CO}_{\mathbf{2}} \mathbf{e}\right)\end{array}$ & $\begin{array}{c}\text { Percentage } \\
\text { contribution }\end{array}$ & $\begin{array}{c}\text { Carbon footprint } \\
\text { during COVID-19 } \\
\text { (tonsCO }\end{array}$ & $\begin{array}{c}\text { Percentage } \\
\text { contribution }\end{array}$ \\
\hline Transportation & 6519 & $36 \%$ & 48.911 & $0.6 \%$ \\
\hline Electricity & 10913.82 & $60 \%$ & 7664.0688 & $98 . \%$ \\
\hline Waste generation & 891.3 & $5 \%$ & 89.47 & $1.4 \%$ \\
\hline Total & 18324.12 & $\mathbf{1 0 0 \%}$ & $\mathbf{7 8 0 2 . 4 5}$ & $\mathbf{1 0 0 \%}$ \\
\hline
\end{tabular}

It is noteworthy that though the overall amount of waste has been decreased, the percentage of food waste, hard plastics, and shopping bags was found to increase. Although the cafeterias throughout the university were closed, this increase can be associated with the extended stay of employees and their families inhabiting residential colonies during the lockdown. A total of $12263.96 \mathrm{~kg}$ carbon emissions is associated with waste management for the year 2020/21 which is mainly given off by the landfilling and trolleys used for the waste management.

Total carbon emission from the university under normal circumstances was found to be about 18360.62 tons $\mathrm{CO}_{2}$ /year from the scope of transportation, electricity, and waste generation. The main contributor is electricity, which is generating 10913.82 tons of $\mathrm{CO}_{2}$ per year, followed by transportation at 651982 tons $\mathrm{CO}_{2}$ per year, and waste generation at 927.8 tons $\mathrm{CO}_{2}$ per year. The dominant sector is electricity which is $59 \%$ of total carbon emission followed by transportation and waste generation at $36 \%$ and $5 \%$ respectively. The overall quantity of carbon footprint at the University of Punjab for the reference year 2019/20 was equivalent to $50.303 \mathrm{GHG}$ emissions/day or 0.52 metric tons $\mathrm{CO}_{2}$ per person per year.

The carbon footprint assessment findings though not directly comparable to other higher education institutes around the world due to variances in adapted methodology, variable system boundary and functional unit, the disparity in the number of employees, students, capital assets and area of the building, etc., a few commonalities have been recorded. Many researchers (Clabeaux 2017; Ozawa-Meida et al., 2013; Ridhosari and Rahman 2020; Sangwan et al., 2018; Thapelo et al., 2011) have reported that the main sources of CF in Universities were Electricity, Transportation, waste transport, and its treatment. Clemson University that hired an external consulting company to calculate Clemson's GHGs emissions, revealed that its main campus in 2014 was producing 95000 metric tons of $\mathrm{CO}_{2} \mathrm{e}$ where $49 \%$ of GHGs emissions were contributed through electricity (Clabeaux 2017). The overall carbon footprint of UK University in $2008 / 2009$ was estimated to be 19,273 metric tons $\mathrm{CO}_{2} \mathrm{e}$ where the electricity-related emissions contributed about 79\% of overall GHGs emissions (Ozawa-Meida et al., 2013). The total carbon footprint from the University of Cape Town's for the year 2007 was evaluated to be around 83,400 tons $\mathrm{CO}_{2} \mathrm{e}$, the relative share of electricity was about $81 \%$, while emissions from transportation and waste generation contributed about $18 \%$ and $1 \%$ respectively (University of Cape Town. Energy Research Centre et al., 2011) The BITS Pilani Indian University was producing about 16500 metric tons $\mathrm{CO}_{2}$ e GHGs emissions. It was observed that electricity production accounted for $50 \%$, waste-related activities have contributed about $48.9 \%$ whereas GHGs emissions were $1.1 \%$ from petrol and diesel (Sangwan et al., 2018). The study of University Pertamina also concluded electricity is the largest carbon emissions contributor followed by transportation (6.66 \%) and waste generation (1.04\%). The overall quantity of carbon footprint at the University of Pertamina was around 1351.98 metric tons of $\mathrm{CO}_{2} \mathrm{e}$ which is equal to 0.52 metric tons of $\mathrm{CO}_{2}$ per person per year (Ridhosari and Rahman, 2020). (Yañez et al., 2019) reported that the University of Talca, Chile has been affected highly by the transportation sector regarding $\mathrm{CO}_{2} \mathrm{eq}$

The study found that during COVID-19 lockdown 2020/21, the carbon footprint of PU declined to 7802.45 tons from 18324.12 tons that correspond to 21.37658 of $\mathrm{GHG}$ emissions/day. The decline can be attributed to the dissolution of various on-campus operations. The overall carbon footprint was reduced to $57.41978 \%$. That includes a substantial $99 \%$ reduction in scope 1, 29.77648\% decrease in scope 2 , and $89.96185 \%$ decline in scope 3 . The largest contribution pre covid-19 almost (60\%) and during COVID-19 (98\%) were recognized to be contributed from electricity consumption. The highest decline (99\%) from transportation activities can be attributed to the commute ban for students and university transportation services that additionally leads to reduced air pollution. The significant input of electricity consumption in the carbon footprint of PU during its closure is noteworthy. Though the conventional academic activities have been suspended during the lockdown, the share was found to be relatively 
higher than anticipated. The higher allocation of electricity reflects its importance to sustaining campus operations and is mainly contributed from residential colonies, online teaching, and ongoing research activities.

\section{Conclusion}

GHGs inventories have evolved as an effective tool for academia to better understand their effects on the environment and needed efforts towards sustainability. We chose the University of the Punjab, Quaid-e-Azam campus to assess the carbon footprint before and during the COVID-19 lockdown. The empirical evidence suggests that Pakistan's largest institution emits about 0.52 tones CO2 per capita/year which reduced to about 0.22 tones CO2 per capita/year during the University closure. The lockdown provided an opportunity to assess the extent and need for environmental improvement by transforming our unrestricted resource consumption and establishing goals for a greenhouse gas emission reduction program. The study concludes that, while an institution's carbon footprint was reduced to more than half (57\%) during the closure, it could not be reduced to zero. A certain extent of dynamism and energy is linked to maintain and sustain an institution. Existing carbon footprint dynamics specify electricity as the most significant contributor. The prevalent obligation of taking online classes from campus also demands a substantial consumption of utilities. The incorporation of renewable and sustainable energy generation alternatives like solar systems can help reduce the associated GHG emissions. In terms of transportation activities, there is a need to promote bus travel and walk as a means for commute within the university. Students should be discouraged from personal vehicles usage and rely more on university shuttle services. Capacity building related to waste management is imperative, the $3 R$ approach and 3 bin system should be familiarized in the University. If these reforms are executed through management intervention, the University of the Punjab can lead by example and lay the foundation for GHG reduction in other institutions of Pakistan as well.

\section{References}

Ahorsu D.K., Lin C.Y., Imani V., Saffari M., Griffiths M.D. and Pakpour A.H. (2020), The fear of COVID-19 scale: development and initial validation, International Journal of Mental Health \& Addiction, 1-9.

Bao W. (2020), COVID-19 and online teaching in higher education: A case study of Peking University, Human Behavior and Emerging Technologies, 2(2), 113-115.

Brander A.M., Sood A., Wylie C., Haughton A., Lovell J., Reviewers I. and Davis G. (2011), Electricity-specific emission factors for grid electricity. Econometrica, 1-22.

Brander M. (2012), Greenhouse Gases, $\mathrm{CO}_{2}, \mathrm{CO}_{2 \mathrm{e}}$, and Carbon: What Do All These Terms Mean?, Econometrica, 3

Cebrián G. and Junyent M. (2015), Competencies in Education for Sustainable Development: Exploring the Student Teachers' Views, Sustainability, 2768-2786.

Clabeaux R.J. (2017), Building a Carbon Footprint of Clemson University's s Main Campus, Doctoral dissertation, Clemson University, Tiger prints. 2731.
Dahlén L. and Lagerkvist A. (2008), Methods for household waste composition studies, Waste Management, 28, 1100-1112.

Disterheft A., Caeiro S., Azeiteiro U.M., Leal W. (2019), Sustainable universities a study of critical success factors for participatory approaches, International Journal of Sustainability in Higher Education, 16(5), 748-771.

Education H. and Development S. (2020). Selective annotated bibliography HEDBIB: International Bibliographic Database on Higher Education.

Filimonau V., Derqui B. and Matute J. (2020), The COVID-19 pandemic and organizational commitment of senior hotel managers, International Journal of Hospital Management, 91, 102659

Findler F., Schönherr N. and Lozano R. (2019), Assessing the impacts of higher education institutions on sustainable development-an analysis of tools and indicators, Sustainability, 11(1), 59.

Hendrickson C., Joshi S., Matthews H.S. and Mcmichael F.C. (1998), Economic Input-Output Based Life-Cycle Assessment ( EIO-LCA ). Sustainability Design. Mental.

Hussain T., Eskildsen J., Edgeman R., Ismail M., Shoukry A.M. and Gani S. (2019), Imperatives of Sustainable University Excellence, Sustainability, 11(19), 5242.

Jarillo M.P., Pedraza L., Ger P.M. and Bocos E. (2019), Challenges of Online Higher Education in the Face of the Sustainability Objectives of the United Nations: Carbon Footprint, Accessibility, and Social Inclusion. Sustainability. 11(20), 5580.

Khan W.M. and Siddiqui S. (2017), Estimation of greenhouse gas emissions by household energy consumption: a case study of Lahore, Pakistan. Pakistan Journal of Meteorology, 14(7).

Krook J., Svensson N. and Eklund M. (2012), Landfill mining: A critical review of two decades of research, Waste Management, 32, 513-520.

Letete T., Mungwe N.W., Guma M. and Marquard A. (2011), Carbon footprint of the University of Cape Town, Journal of Energy in Southern Africa, 22(2), 2-12.

Lorena A., Albert M. and Maria D. (2013), carbon footprint analysis: towards a projects evaluation model for promoting sustainable development, Procedia Economics \& Finance,. 6, 353-363.

Mungwe N.W., Guma M. and Marquard A. (2011) University of Cape Town. Energy Research Centre, T.C.M., Journal of Energy in Southern Africa, 22, 2-12.

Murphy M.P. (2020), COVID-19 and emergency elearning: Consequences of the securitization of higher education for post-pandemic pedagogy, Contemporary Security Policy, 41(3), 492-505.

Owojori O., Edokpayi J.N., Mulaudzi R., Odiyo J.O. (2020). Characterization, recovery and recycling potential of solid waste in a University of a developing economy, Sustainability, 1-17.

Ozawa-Meida L., Brockway P., Letten K., Davies J. and Fleming P. (2013), Measuring carbon performance in a UK University through a consumption-based carbon footprint: De Montfort University case study, Journal of Cleaner Production, 56, 185198.

Palanivel T.M. and Sulaiman H. (2014), Generation and Composition of Municipal Solid Waste (MSW) in Muscat, Sultanate of Oman. APCBEE Procedia, 10, 96-102. 
PE International (2013), Introduction to Life Cycle Assessment (GaBi Paper Clip Video Tutorial), Private Equity International, 9-27.

Rana R., Hammad M. and Ather S. (2020), Change in surgical practice amidst COVID-19; example from a tertiary care center in Pakistan, Annals of Medicine \& Surgery, 54, 79-81.

Ridhosari B. and Rahman A. (2020), Carbon footprint assessment at Universitas Pertamina from the scope of electricity, transportation, and waste generation: Toward a green campus and promotion of environmental sustainability, Journal of Cleaner Production, 246.

Sangwan K.S., Bhakar V., Arora V. and Solanki P. (2018), Measuring carbon footprint of an Indian University using life cycle assessment, Procedia CIRP, 69, 475-480.

Šenitková I. and Bednárová P. (2015). Life cycle assessment. JP Journal of Heat \& Mass Transfer, 11, 29-42.

Sevenster M.N. (2013), Life cycle assessment, Sustainable Dairy Production, 31-53.

WBCSD, WRI. (2012). A corporate accounting and reporting standard. Greenhouse Gas Protocol. World Resources Institute, 116.

Yan Y., Zhang H., Meng J., Long Y., Zhou X., Li Z., Wang Y. and Liang Y. (2019), Carbon footprint in building distributed energy system: An optimization-based feasibility analysis for potential emission reduction, Journal of Cleaner Production, 239, 117990.

Yañez P., Sinha A., Vásquez M. (2019), Carbon Footprint Estimation in a University Campus: Evaluation and Insights, Sustainability, 12, 181. 